\title{
QT Interval Shortening After Bariatric Surgery Depends on the Applied Heart Rate Correction Equation
}

\author{
Erik K. Grasser ${ }^{1} \cdot$ Barbara Ernst $^{2} \cdot$ Martin Thurnheer $^{2} \cdot$ Bernd Schultes $^{2}$
}

\begin{abstract}
Background A shortening of electrocardiographic QT interval has been observed in obese subjects after weight loss, but previous results may have been biased by inappropriate heart rate (HR) correction.

Methods Electrocardiography (ECG) recordings of 49 (35 females) severely obese patients before and 12 months after Roux-en-Y gastric bypass (RYGB) surgery were analysed. QT interval (QTc) was calculated by using four different equations, i.e. Bazett, Fridericia, Framingham and Hodges.

Results Irrespectively of the used correction formula, QTc interval length was reduced after the surgery $\left(\mathrm{QTc}_{\mathrm{Bazett}}-31 \pm 18 \mathrm{~ms}\right.$; $\mathrm{QTc}_{\text {Fridericia }}-12 \pm 15 \mathrm{~ms} ; \mathrm{QTc}_{\text {Framingham }}-14 \pm 15 \mathrm{~ms}$; QTc $\mathrm{Codges}_{\text {Hos }}$ $-9 \pm 15 \mathrm{~ms}$; all $P \mathrm{~s}<0.001$ ), but $\mathrm{QTc} \mathrm{Bazett}_{\mathrm{B}}$ reduction was significantly greater than the reduction in QTc calculated upon the other three equations (all $P_{\mathrm{s}}<0.001$ ). Moreover, changes in $\mathrm{QTc}_{\text {Bazett }}(P<0.001)$ but not in $\mathrm{QTc}_{\text {Fridericia, }} \mathrm{QTc}_{\text {Framingham }}$ and $\mathrm{QTc}_{\text {Hodges }}$ (all $P \mathrm{~s}>0.05$ ) were significantly correlated with concurrent changes in HR. Multivariate regression analyses revealed a significant independent association of serum insulin levels with
\end{abstract}

Bernd Schultes

bernd.schultes@eswiss.center

Erik K. Grasser

erikkonrad.grasser@unifr.ch

Barbara Ernst

barbara.ernst@eswiss.center

Martin Thurnheer

martin.thurnheer@eswiss.center

1 Department of Medicine/Physiology, University of Fribourg, Fribourg, Switzerland

2 eSwiss Medical and Surgical Center, Interdisciplinary Obesity Center, St. Gallen, Switzerland
$\mathrm{QTc}_{\text {Fridericia, }}$ QTc $\mathrm{Framingham}_{\text {Fra }}$ aTc $\mathrm{Q}_{\text {Hodges }}$ values (all $P \mathrm{~s}<0.05$ ) preoperatively, whilst changes in QTc interval length after the surgery were not consistently associated to concurrent changes in metabolic traits.

Conclusions Our data show that the extent of weight lossassociated QTc interval shortening largely depends on the applied HR correction equation and appears to be overestimated when the most popular Bazett's equation is used.

Keywords Prolonged QTc · Cardiac hyperpolarization · Morbid obesity $\cdot$ Roux-en Y gastric bypass · Bazett's formula

\section{Introduction}

Obesity is associated with an increased risk for cardiovascular diseases and premature death $[1,2]$. An abnormal ventricular repolarization, which predisposes to sudden death upon cardiac arrhythmia [3], may contribute to the increased mortality risk since obesity has been found to be associated with a high prevalence of a prolonged QT interval in electrocardiographic (ECG) recordings [4]. Furthermore, weight loss, in particular when induced by bariatric surgery, has been found to reduce QT interval (QTc) length in many studies (for overview see Table 1) [5-22]. However, the validity of this observation has been challenged by one previous study [9] that demonstrated that the significance of QTc shortening upon weight loss gets lost when the QT interval is corrected for heart rate (HR) by using Fridericia or Framingham correction equation instead of the most commonly used Bazett equation. Indeed, the Bazett equation is known to be most sensitive to biasing effects of HR which appear to be particular important in the context of weight loss since weight loss is often accompanied by a reduction in HR. It should be noted, however, that the extent of 


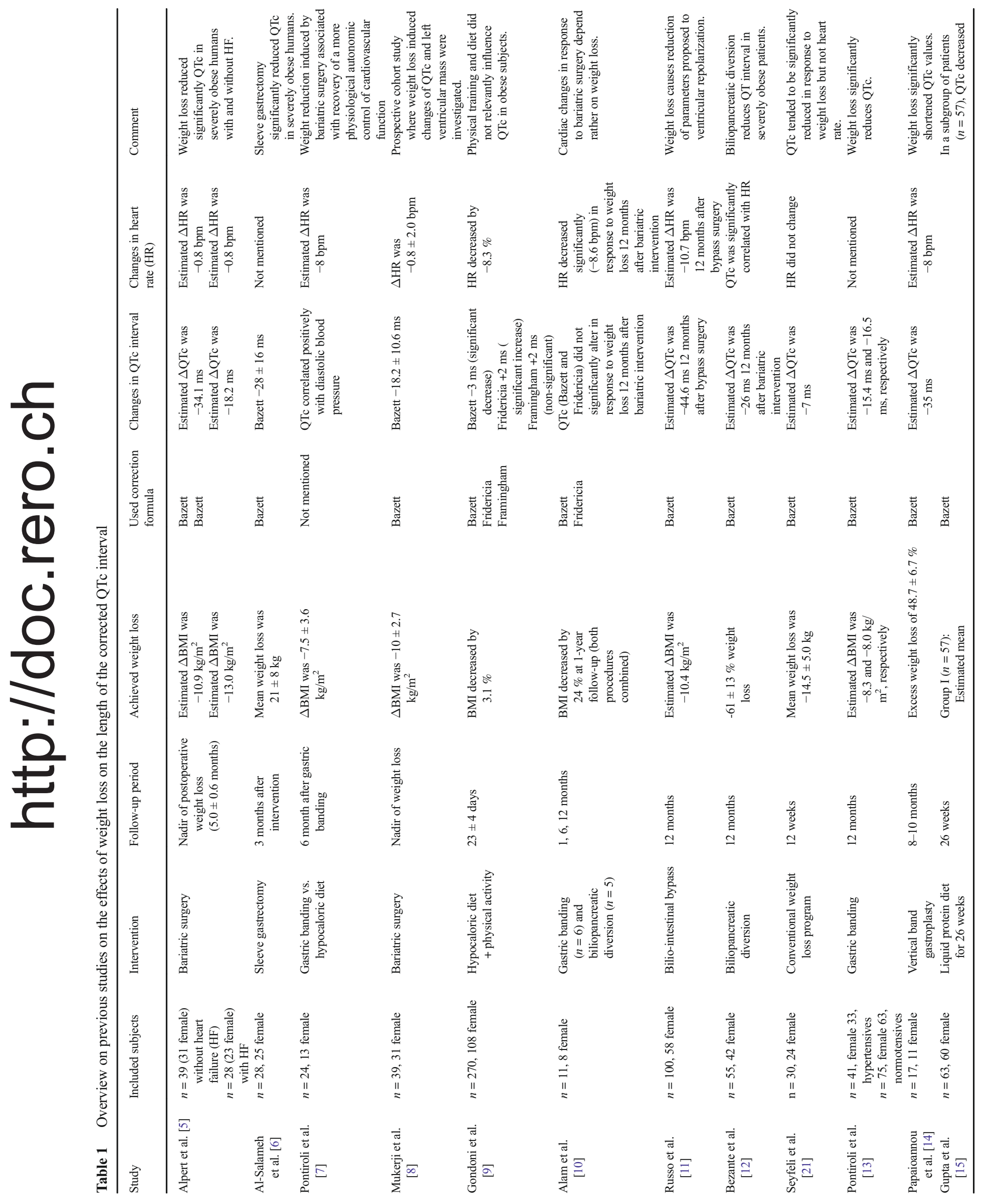


weight loss induced by a hypocaloric diet and exercise in the abovementioned negative study [9] was only moderate, i.e. a BMI reduction of $-1.2 \mathrm{~kg} \mathrm{~m}^{-2}$. Thus, the finding of unchanged QTc interval length after weight loss in this study may not pertain to greater amounts of weight loss as typically achieved by bariatric surgery. Support for this assumption may generate from a recent meta-analysis of 11 studies that investigated QT intervals after weight loss [23]. Here, it was found that the reduction of QTc interval length was more pronounced in the six studies in which the weight loss was achieved by bariatric surgery than in the five studies that used non-surgical measures.

An intriguing previous finding in the context of QTc interval investigation after bariatric surgery was that a shortening was already observed 4 weeks after biliopancreatic diversion (BPD) surgery in one study [12]. Moreover, despite a marked progressive weight loss, a further shorting of QTc was not observed thereafter [12]. This finding suggests that QTc interval shorting might not only represent a consequence of weight loss $[6,12]$ but could also result from dramatic metabolic changes as a consequence of bariatric surgery. Insulin may play a particular role in this context, since bariatric surgery has been shown to rapidly reduce circulating insulin levels [24]. Moreover, several previous cross-sectional studies have revealed an independent association between circulating insulin levels and QTc interval length $[25,26]$. Interventional studies, however, have revealed a less consistent picture where intravenous insulin infusion acutely increased QTc interval length in normal weight [27] but not in obese subjects [28] under euglycemic conditions.

Therefore, we addressed two questions in the present study: Firstly, does, and if so to what extent, shorting the QTc interval length after bariatric surgery depends on the used HR correction equation, and, secondly, are changes in QTc interval length related to concurrent changes in circulating insulin levels or other metabolic traits?

\section{Methods}

\section{Selection of Patients and Study Design}

For the purpose of our study, we extracted data from a large, prospectively maintained database including data from severely obese subjects who have undergone bariatric surgery. Inclusion criteria for the study were the existence of an ECG recording within 3 months before and 1 year after bariatric surgery. Exclusion criteria were the intake of any drugs known to affect QTc interval length [29], a known heart disease and any kind of arrhythmia or bundle blocks in the ECG recordings. We identified 49 severely obese patients who fulfilled these criteria. Concurrent clinical data including anthropometric measures, blood pressure and metabolic blood parameters were also extracted from the database. Nine $(18 \%)$ of 49 obese patients had type 2 diabetes with 5 of them taking oral anti-diabetic drugs alone and 4 of them in combination with insulin.

\section{Surgical Procedure}

All procedures were carried out by the same surgeon (Martin Thurnheer). Seven subjects underwent a standard proximal Roux-en Y gastric bypass (RYGB) procedure and 42 subjects a distal RYGB variant as previously described [30].

\section{Clinical Assessments}

All subjects underwent a standardized clinical assessment before and 1 year after RYGB surgery. This included a venous blood sampling in the morning (8:00-10:00 h) after overnight fasting, the measurement of body weight, waist circumference, brachial blood pressure by use of appropriate, arm circumference adjusted cuffs (OSZ 5 Easy, Welch Allyn, Jungingen, Germany), an bioelectrical impedance analysis for determination of body composition (Nutriguard-M, DataInput GmbH, Darmstadt, Germany) and a 12-lead ECG recording (Schiller CS-200, Schiller Medizintechnik GmbH, Germany), which was measured in a supine position after a rest of at least $10 \mathrm{~min}$. Glucose, insulin, triglycerides, lowdensity and high-density lipoproteins and high sensitive Creactive protein (hsCRP) concentrations were measured in serum samples.

\section{ECG Analyses}

Electronically recorded ECGs were analysed in accordance to current recommendations [31]. HR was calculated upon respective RR intervals. QTc was measured from the earliest onset of the Q-wave to the latest end of the T-wave. In the presence of a U-wave, the T-wave end was defined by the nadir between the two of them. At least three consecutive beats were analysed and respective QT intervals were averaged for further analysis. To avoid inter-observer bias, all analyses of ECG recordings were performed by one examiner (Erik Konrad Grasser).

Correction of QT intervals for HR (RR interval) was performed by using the following four established equations: Bazett's equation $\left(\mathrm{QTc}=\mathrm{QT} / \mathrm{RR}^{0.5}\right)$ [32], Fridericia's equation $\left(\mathrm{QTc}=\mathrm{QT} / \mathrm{RR}^{0.33}\right)[33]$, Framingham's equation $(\mathrm{QTc}=\mathrm{QT}+0.154(1000-\mathrm{RR}))[34]$ and Hodges's equation $(\mathrm{QTc}=\mathrm{QT}+1.75($ heart rate -60$))[35]$.

QT dispersion (QTD) was assessed as the difference between the maximum QT interval $\left(\mathrm{QT}_{\max }\right)$ and the minimum QT interval $\left(\mathrm{QT}_{\min }\right)$ length across the 12 leads. Corrected QT dispersion (QTcD) was calculated by correcting $\mathrm{QT}_{\text {max }}$ and $\mathrm{QT}_{\min }$ by using the four different equations, i.e. Bazett, Fridericia, Framingham 
and Hodges $\left(\mathrm{QTcD}_{\text {Bazett }}, \mathrm{QTcD_{ \text {Fridericia } }}, \mathrm{QTcD_{ \text {Framingham } } \text { and }}\right.$ $\mathrm{QTcD_{ \text {Hodges } }}$ ), before subtracting respective $\mathrm{QTc} \mathrm{c}_{\text {min }}$ from $\mathrm{QTc}_{\max }$ values.

\section{Calculations and Statistical Data Analysis}

The following indices were calculated upon the assessed data: homeostasis model assessment (HOMA), i.e. an estimate of insulin resistance (HOMA-IR), was calculated by using the following formula: HOMA-IR $=$ [fasting insulin $\left(\mu \mathrm{IU} \mathrm{mL}{ }^{-1}\right) \times$ fasting glucose $\left.\left(\mathrm{mmol} \mathrm{L}^{-1}\right)\right] / 22.5$ [36]. Excessive weight loss (EWL \%) was calculated as (preoperative weight minus current weight) / (preoperative weight minus height $[\mathrm{cm}]+100) \times 100$. Total weight loss $[\mathrm{kg}]$ was calculated as current weight minus preoperative weight and relative weight loss [\%] as (current weight minus preoperative weight) / (preoperative weight) $\times 100$.

All data are reported as means \pm standard deviation (SD). Variables were tested for normality using the D'Agostino Pearson omnibus normality test. Pairwise comparisons were performed using a paired Student's $t$ test. Repeated measures ANOVA with the Newman-Keuls post hoc testing was used to compare between the four corrected QT intervals and dispersions. Prevalence of patients with QTc prolongation $>440 \mathrm{~ms}$ before vs. after RYGB surgery was compared by McNemar test. Pearson correlation analysis was used to assess associations between QTc changes in QTc intervals (i.e. $\Delta \mathrm{QTc}=\mathrm{QTc}$ after RYGB - QTc before RYGB) and other concurrently assessed variables. Multivariate regression analyses were performed to detect independent associations. All reported $P$ values are two sided. For all tests, significance was set at $P<0.05$.

\section{Results}

Data on anthropometric, cardiovascular and metabolic variables before and 1 year after the RYGB surgery are provided in Table 2. The average weight loss across the 1-year postoperative period was $48.9 \pm 14.8 \mathrm{~kg}$ which translates to a relative weight loss of $37.2 \pm 6.5 \%$, a BMI loss of $17.3 \pm 4.4 \mathrm{~kg} \mathrm{~m}^{-2}$ and a EWL of $72.4 \pm 18.6 \%$ (all $P<0.001$ ). Body fat mass (FM), percentage FM and waist circumference were also significantly reduced after the surgery (all $P \mathrm{~s}<0.001$ ). Importantly, HR decreased on average by $19.1 \pm 10.4 \mathrm{bpm}$, as did SBP and DBP (all $P \mathrm{~s}<0.001$ ).

Metabolic blood variables were markedly improved after the surgery as glucose, insulin, HOMA-IR, hsCRP, triglycerides, total cholesterol and low-density lipoprotein levels were significantly lower and high-density lipoprotein levels significantly higher after than before the surgery (all $P \mathrm{~s}<0.05$ ).

\section{QTe Interval Length Before and After RYGB Surgery}

QTc values calculated upon the different correction equations before and after the RYGB surgery are provided in Table 3. Before the RYGB surgery, QTc intervals calculated upon the Bazett's equation were significantly longer than calculated upon the three other equations ( $P<0.001$ for all comparisons).

One year after the RYGB surgery, QTc Bazett $_{\text {interval length }}$ was on average $-30.6 \pm 18.2 \mathrm{~ms}$ shorter than before the surgery $(P<0.001)$. The extent of QTc shortening was much smaller when the other three correction equations were used $\left(\mathrm{QTc}_{\text {Fridericia }}-11.5 \pm 14.7 \mathrm{~ms}, \mathrm{Qtc}_{\text {Framingham }}-13.5 \pm 14.8 \mathrm{~ms}\right.$, $\mathrm{QTc}_{\text {Hodges }}-9.0 \pm 14.6 \mathrm{~ms}$; all $P \mathrm{~s}<0.001$ for comparison with $\Delta \mathrm{QTc}_{\text {Bazett }}$; Fig. 1) but still significant (all $P \mathrm{~s}<0.001$ for comparison with corresponding preoperative values).

The number of patients showing a $\mathrm{QTc}_{\mathrm{Bazett}}$ interval length of greater than $440 \mathrm{~ms}$ significantly decreased from 14 preoperatively to 2 postoperatively $(P<0.001)$, whilst with the other correction equations, only 3 to 1 patients showed a QTc interval length $>440 \mathrm{~ms}$ before the surgery and none of the patients after the surgery.

\section{Correlation and Multivariate Regression Analyses Before RYGB Surgery}

Preoperative $\mathrm{QTc}_{\mathrm{Bazett}}$ did not correlate with any other of the assessed variables $(P>0.05)$, whilst QTc $\mathrm{Tc}_{\text {Fridericia }}$ inversely correlated with body weight $(r=-0.40 ; P=0.004)$, hip circumference $(r=-0.32 ; P=0.03)$ and waist circumference $(r=-0.35 ; P=0.02)$. QTc $\mathrm{Pr}_{\text {Framingham }}$ inversely correlated with HR $(r=-0.29 ; P=0.04)$, weight $(r=-0.42 ; P=0.003)$, hip circumference $(r=-0.34 ; P=0.02)$ and waist circumference $(r=-0.36 ; P=0.01) . \mathrm{QTc}_{\text {Hodges }}$ was inversely correlated with weight $(\mathrm{r}=-0.34 ; P=0.02)$.

Multivariate regression analysis indicated no significant association of any of the assessed variable with QTc $\mathrm{Bazett}_{\text {be- }}$ fore the surgery. In contrast, respective analysis on the other three QTc variables, i.e. QTc Fridericia $_{\text {Q }} \mathrm{QTc}_{\text {Framingham }}$ and $\mathrm{QTc}_{\text {Hodges}}$, showed a very consistent picture with preoperative values being significantly related to HR and insulin (Table 4).

\section{Correlation and Multivariate Regression Analyses After RYGB Surgery}

In response to RYGB surgery, changes in QTc interval length $(\Delta \mathrm{QTc})$ correlated with changes in $\mathrm{HR}(\Delta \mathrm{HR})$ when using the Bazett's equation $(P<0.001)$, which could not be found when using Fridericia's $(P=0.73)$, Framingham's $(P=0.91)$ or Hodges's equation $(P=0.88)$ (Fig. 2). Interestingly, irrespectively of the used correction equation, changes in the QTc interval length $(\triangle \mathrm{QTc})$ did not correlate with preoperative QTc values (all $P \mathrm{~s}>0.09$; Fig. 3). 
Table 2 Anthropometric, blood and cardiovascular data of subjects before (pre) and 12 months after (post) Roux-en-Y gastric bypass (RYGB)

\begin{tabular}{|c|c|c|c|c|}
\hline Variable & $\begin{array}{l}\text { Pre } \\
\text { Mean } \pm \text { SD }\end{array}$ & $\begin{array}{l}\text { Post } \\
\text { Mean } \pm \text { SD }\end{array}$ & $P$ value & $n$ \\
\hline Age, years & $38.7 \pm 11.0$ & $40.1 \pm 11.0$ & $<0.001$ & 49 \\
\hline Height, m & $1.67 \pm 0.10$ & $1.67 \pm 0.10$ & 1.0 & 49 \\
\hline Weight, $\mathrm{kg}$ & $130.0 \pm 25.1$ & $81.1 \pm 15.2$ & $<0.001$ & 49 \\
\hline Body mass index, $\mathrm{kg} \mathrm{m}^{-2}$ & $46.2 \pm 6.7$ & $29.0 \pm 4.5$ & $<0.001$ & 49 \\
\hline Waist, $\mathrm{cm}$ & $131 \pm 17$ & $94 \pm 11$ & $<0.001$ & 46 \\
\hline Hip, cm & $140 \pm 15$ & $106 \pm 10$ & $<0.001$ & 46 \\
\hline Fat mass, $\mathrm{kg}$ & $61.2 \pm 15.2$ & $23.1 \pm 9.5$ & $<0.001$ & 43 \\
\hline Fat mass, $\%$ & $47.3 \pm 6.4$ & $28.1 \pm 8.8$ & $<0.001$ & 43 \\
\hline Total Cholesterol, $\mathrm{mmol} \mathrm{L}^{-1}$ & $4.9 \pm 1.1$ & $3.3 \pm 0.7$ & $<0.001$ & 45 \\
\hline Low density lipoprotein, $\mathrm{mmol} \mathrm{L}^{-1}$ & $2.8 \pm 0.8$ & $1.4 \pm 0.5$ & $<0.001$ & 43 \\
\hline High density lipoprotein, $\mathrm{mmol} \mathrm{L}^{-1}$ & $1.3 \pm 0.3$ & $1.4 \pm 0.3$ & 0.03 & 45 \\
\hline Triglycerides, $\mathrm{mmol} \mathrm{L}^{-1}$ & $1.9 \pm 1.1$ & $1.1 \pm 0.5$ & $<0.001$ & 45 \\
\hline High sensitive C-reactive protein, $\mu \mathrm{U} \mathrm{mL}^{-1}$ & $9.7 \pm 6.8$ & $1.4 \pm 1.9$ & $<0.001$ & 44 \\
\hline Glucose, $\mathrm{mmol} \mathrm{L}^{-1}$ & $6.1 \pm 2.3$ & $4.8 \pm 0.9$ & 0.001 & 30 \\
\hline Insulin, $\mathrm{mU} \mathrm{L}^{-1}$ & $18.6 \pm 11.5$ & $4.8 \pm 4.6$ & $<0.001$ & 38 \\
\hline HOMA-IR & $5.5 \pm 4.7$ & $1.3 \pm 1.7$ & $<0.001$ & 30 \\
\hline Heart rate, bpm & $79.6 \pm 10.0$ & $60.6 \pm 9.0$ & $<0.001$ & 49 \\
\hline Systolic blood pressure, $\mathrm{mmHg}$ & $132.7 \pm 14.6$ & $117.7 \pm 13.0$ & $<0.001$ & 41 \\
\hline Diastolic blood pressure, $\mathrm{mmHg}$ & $87.7 \pm 10.4$ & $74.1 \pm 12.9$ & $<0.001$ & 41 \\
\hline
\end{tabular}

Statistical analysis was performed using a paired students $t$ test, and $P<0.05$ was considered as significant difference

$n$ number of patients, $S D$ standard deviation, HOMA-IR homeostasis model assessment of insulin resistance
Postoperative changes in the $\mathrm{QTc}_{\mathrm{Bazett}}$ interval length $\left(\Delta \mathrm{QTc} \mathrm{c}_{\text {Bazett }}\right)$ were significantly correlated with changes in BMI $(r=0.32 ; P=0.03)$, absolute weight loss $(r=0.31 ; P<0.05)$, HR $(r=0.60 ; P<0.001)$ and hsCRP levels $(r=0.38 ; P<0.05)$. Postoperative changes in $\mathrm{QTc}_{\text {Hodges }}$ were significantly correlated with changes in total cholesterol $(r=0.37 ; P<0.05)$ and LDL $(r=0.33$;
$P<0.05)$ levels. No bivariate correlations were found between the assessed variables and changes in $\mathrm{QTc}_{\text {Fridericia }}$ and $\mathrm{QTc}_{\text {Framingham }}$ values.

Multivariate regression analysis revealed that changes in $\mathrm{QTc}_{\text {Bazett }}$ were independently associated with changes in HR $\left(R^{2}=0.29 ; B=0.69 ; \mathrm{SEM}=0.26 ; P<0.05\right)$ and changes in $\mathrm{QTc}_{\text {Hodges }}$ were independently associated with changes in total
Table 3 Calculations of average QT and corrected QT intervals (QTc) and presentation of patients with QTc $\geq 440 \mathrm{~ms}$ before (pre) and after (post) gastric bypass surgery using four different equations to calculate QTc $(n=49,35$ females $)$

\begin{tabular}{llllll}
\hline & $\mathrm{QT}$ & $\mathrm{QTc}_{\text {Bazett }}$ & $\mathrm{QTc}_{\text {Fridericia }}$ & $\mathrm{QTc}_{\text {Framingham }}$ & $\mathrm{QTc}_{\text {Hodges }}$ \\
Pre, ms & $374 \pm 26$ & $429 \pm 21$ & $410 \pm 20^{\mathrm{b}}$ & $410 \pm 18^{\mathrm{b}}$ & $409 \pm 19^{\mathrm{b}}$ \\
Post, ms & $399 \pm 24$ & $398 \pm 23$ & $398 \pm 19$ & $397 \pm 20$ & $400 \pm 19$ \\
$P$ value $^{\mathrm{a}}$ & $<0.001$ & $<0.001$ & $<0.001$ & $<0.001$ & $<0.001$ \\
Patients $\geq 440 \mathrm{~ms}$ & - & $\mathrm{QTc}_{\text {Bazett }}$ & $\mathrm{QTc}_{\text {Fridericia }}$ & $\mathrm{QTc}_{\text {Framingham }}$ & $\mathrm{QTc}_{\text {Hodges }}$ \\
Pre, $n(\%)$ & - & $14(29 \%)$ & $3(6 \%)$ & $3(6 \%)$ & $1(2 \%)$ \\
Post,$n(\%)$ & - & $2(4 \%)$ & $0(0 \%)$ & $0(0 \%)$ & $0(0 \%)$ \\
$P$ value & - & $<0.001$ & - & - & - \\
\hline
\end{tabular}

All data are expressed as the mean $\pm \mathrm{SD}$, and statistical significance was set at $P<0.05$. No changes were found comparing the postsurgery QTc intervals

$Q T c_{\text {Bazett }} \mathrm{QTc}$ evaluation using Bazett's formula $\left(\mathrm{QTc}=\mathrm{QT} / \mathrm{RR}^{0.5}\right), Q T c_{\text {Fridericia }} \mathrm{QTc}$ evaluation using Friderica's formula $\left(\mathrm{QTc}=\mathrm{QT} / \mathrm{RR}^{0.33}\right), Q^{2} c_{\text {Framingham }} \mathrm{QTc}$ evaluation using Framingham's formula $(\mathrm{QTc}=\mathrm{QT}+0.154$ $(1000-\mathrm{RR})), Q T c_{\text {Hodges }} \mathrm{QTc}$ evaluation using Hodges's formula $(\mathrm{QTc}=\mathrm{QT}+1.75$ (heart rate -60$)$ )

${ }^{a}$ Comparisons between pre and post conditions were performed using a paired $t$ test

${ }^{\mathrm{b}} P<0.005$, statistical significant difference compared with pre-QTc $\mathrm{Bazett}_{\mathrm{B}}$ using repeated measures ANOVA with Newman-Keuls post hoc testing 


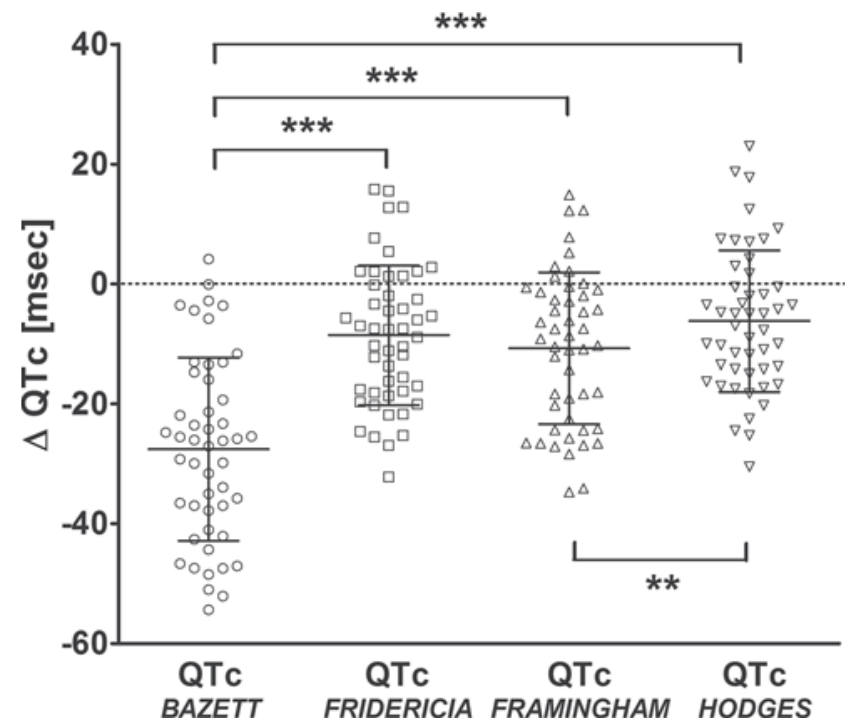

Fig. 1 QTc changes in 49 subjects (35 females) (i.e. QTc after RYGB subtracted by QTc before RYGB $=\Delta \mathrm{QTc}$ ) depicted as scatter dot plot (means $\pm \mathrm{SD}$ ) using four different $\mathrm{QT}$ correction equations (i.e. $\mathrm{QTc} \mathrm{c}_{\mathrm{Bazet}}$, QTc $c_{\text {Fridericia }}$ QT $\mathrm{Cc}_{\text {Framingham }}$ and QTc $\mathrm{Codges}_{\text {Hos }}$. Repeated measures ANOVA with Newman-Keuls post hoc testing was used to compare changes in QTc between the four equations and statistical significance was set at $P<0.05$. ${ }^{*} P<0.01$, statistical significant difference between $\mathrm{QTc}_{\text {Hodges }}$ and $\mathrm{QTc}_{\text {Framingham }}$ and $* * * P<0.005$, statistical significant difference between $\mathrm{QTc} \mathrm{B}_{\mathrm{Bazett}}$ and $\mathrm{QTc}_{\mathrm{Fridericia}}, \mathrm{QTc}_{\mathrm{Framingham}}$ and QTc Hodges $_{\text {Hon }}$

cholesterol $\left(R^{2}=0.3 ; B=16.5 ; \mathrm{SEM}=4.1 ; P=0.001\right)$ and LDL $\left(R^{2}=0.21 ; B=-14.8 ; \mathrm{SEM}=5.7 ; P<0.05\right)$.

\section{QT Dispersion}

QTD values did not significantly change after the RYGB surgery (before $40.0 \pm 14.4$ vs. after $41.7 \pm 14.5 \mathrm{~ms} ; P=0.58$ ). This was also true after correcting QTD for HR by using the correction equations (before vs. after; QTcD Bazett $_{45.2 \pm 16.3}$ vs. $41.1 \pm 14.0 \mathrm{~ms} ; P=0.19 ; \mathrm{QTcD}_{\text {Fridericia }} 43.3 \pm 15.6$ vs. $41.0 \pm 14.1 \mathrm{~ms} ; P=0.47$; $\mathrm{QTcD}_{\text {Framingham }} 40.0 \pm 14.4 \mathrm{vs}$. $41.7 \pm 14.5 \mathrm{~ms} ; P=0.58 ; \mathrm{QTcD}_{\text {Hodges }} 40.0 \pm 14.4 \mathrm{vs}$. $41.7 \pm 14.4 \mathrm{~ms} ; P=0.58)$. Of note, there were differences between QTcD calculated upon the four different equations neither before nor after the RYGB surgery (all $P \mathrm{~s}>0.25$ ).

\section{Discussion}

To our best knowledge, we are the first to show a consistent reduction of QTc interval length by using four different QT correction equations in response to excessive weight loss after undergoing a RYGB surgery procedure. However, the extent of QTc interval shortening clearly depends on the applied correction equation with an overestimation when using Bazett's equation, which also appears to be most sensitive to changes in HR. Furthermore, whilst QTc interval length appears to be cross-sectionally associated with serum insulin levels, postoperative changes in the hormone concentrations as well as in other assessed metabolic variables were not found to be consistently associated with QTc interval shorting recorded 1 year after RYGB surgery. Taken together, our findings clearly support the previous notion of a QTc interval shorting associated with weight loss, the underlying mechanisms of which require further investigations.

An abnormal QTc prolongation represents an independent risk factor for sudden cardiac death [3, 31]. In our study, $29 \%$ of the severely obese patients showed a QTc interval length above $440 \mathrm{~ms}$ when the Bazett formula was used for HR correction. Moreover, the percentage of patients showing a QTc interval length above this cutoff was markedly reduced to $4 \%$ after the RYGB surgery. In light of this finding, it is tempting to conclude that an improvement of ventricular repolarization could represent a relevant factor for the reduction of mortality upon bariatric surgery that has previously been documented in large-scale observational studies [37, 38]. However, this notion is clearly challenged by our observation of substantial reduced patients showing prolonged QTc intervals when a correction equation other than Bazett's has been used. Moreover, the lack of any correlation between the preoperative QTc interval length and respective changes after the surgery renders it rather unlikely that the shorting of QTc intervals represents a normalization of a pathological condition associated with the weight loss. Of note, to date it is not even clear whether the obesity-associated QT interval prolongation and its reduction after weight loss is overall related to the incidence of cardiac arrhythmia that can result in sudden cardiac deaths. Further studies exploiting technologies for

Table 4 Multivariate regression model with $\mathrm{QTc}_{\text {Fridericia, }} \mathrm{QTc}_{\text {Framingham }}$ and $\mathrm{QTc}_{\mathrm{Hodges}}$ as dependent variable prior to $\mathrm{RYGB}$ surgery $(n=49,35$ females)

\begin{tabular}{|c|c|c|c|c|c|c|c|c|}
\hline & \multicolumn{4}{|c|}{ Heart rate } & \multicolumn{4}{|c|}{ Insulin } \\
\hline & $R^{2}$ & $B$ & SEM & $P$ value & $R^{2}$ & B & SEM & $P$ value \\
\hline $\mathrm{QTc}_{\text {Fridericia }}$ & 0.33 & -1.53 & 0.37 & 0.001 & 0.19 & 0.84 & 0.34 & $<0.05$ \\
\hline $\mathrm{QTc}_{\text {Framingham }}$ & 0.36 & -1.48 & 0.34 & 0.001 & 0.19 & 0.80 & 0.31 & $<0.05$ \\
\hline $\mathrm{QTc}_{\text {Hodges }}$ & 0.26 & -1.28 & 0.38 & $<0.01$ & 0.17 & 0.75 & 0.34 & $<0.05$ \\
\hline
\end{tabular}

$H R$ heart rate, SEM standard error of the means 
Fig. 2 Linear regression analysis in 49 subjects ( 35 females) including statistics (Pearson correlation coefficient $r$ and the corresponding $P$ value) for the relation between mean changes in $\mathrm{QTc}_{\text {Bazett }}(\mathbf{a}), \mathrm{QTc}_{\text {Fridericia }}(\mathbf{b})$,

QTc Framingham $_{\text {(c) and }}$ QTc $\mathrm{C}_{\text {Hodges }}$ (d) to mean changes in heart rate (HR) (i.e. HR after RYGB subtracted by HR before $\mathrm{RYGB}=\Delta \mathrm{HR}) . P<0.05$ was considered as statistical significant
A

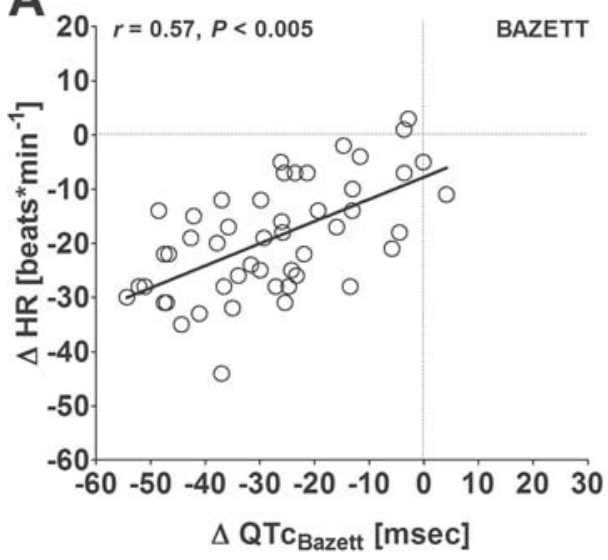

C

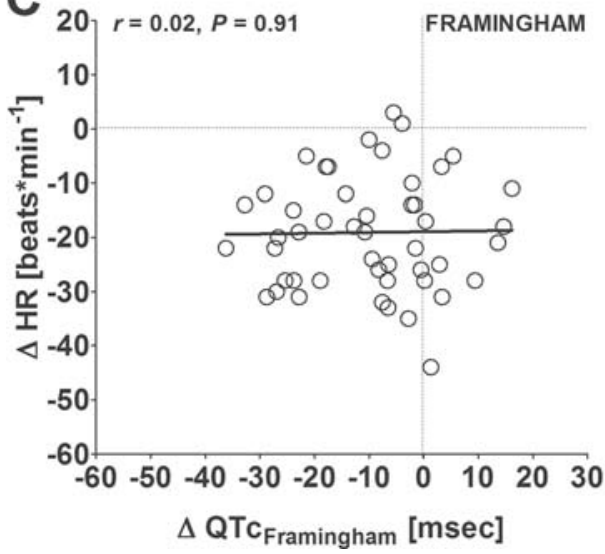

A

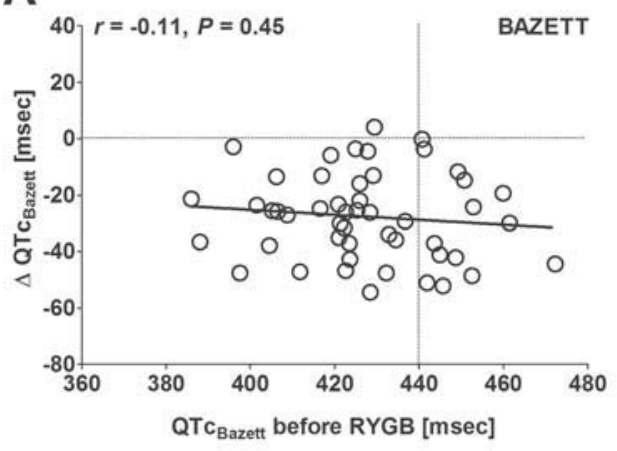

C

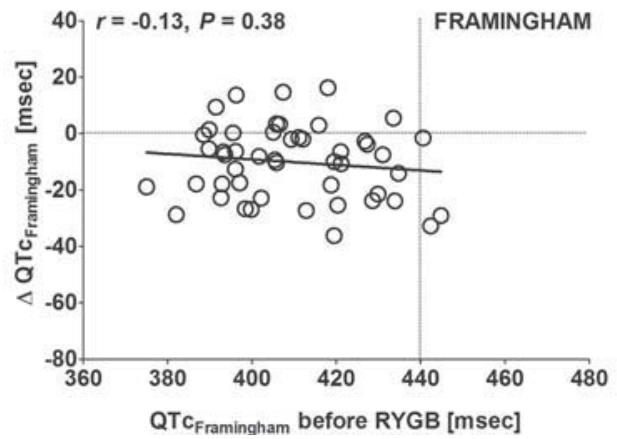

B
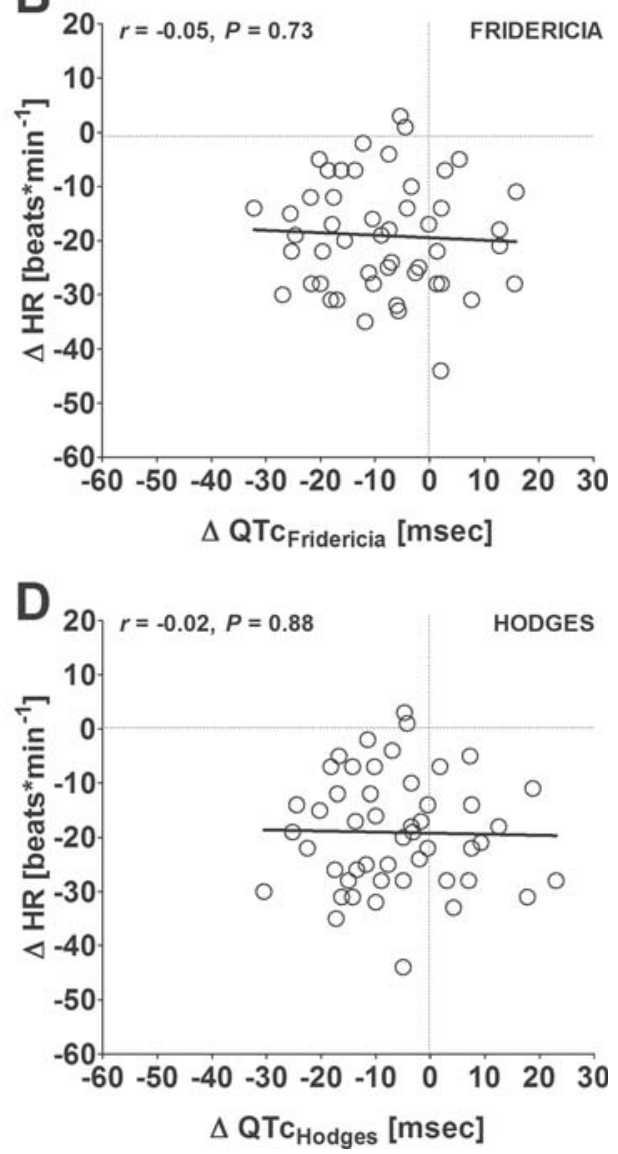

B

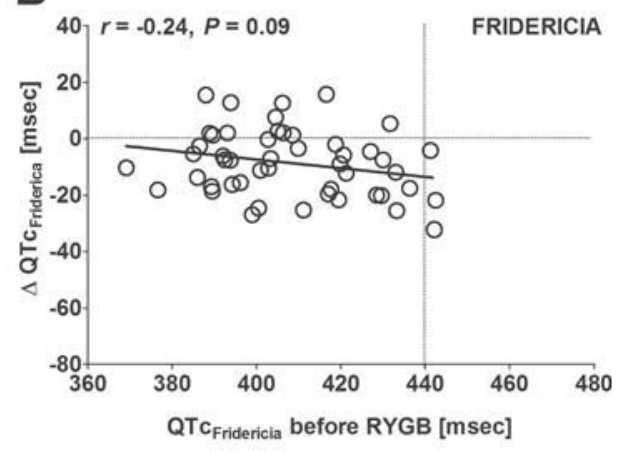

D

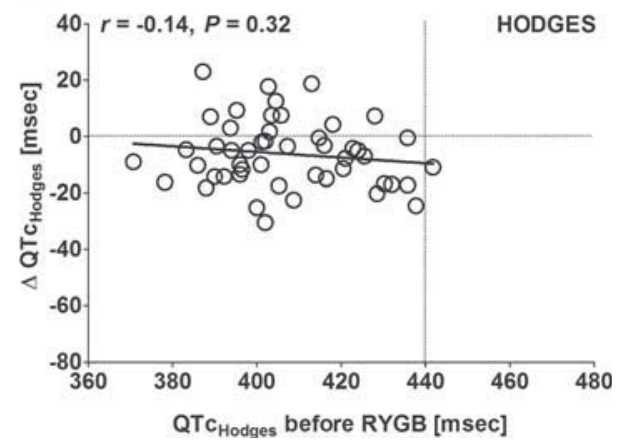


continuous cardiac monitoring such as implantable loop recorders are needed to answer this important question in the future.

The mechanisms underlying QTc interval shortening as a consequence of weight loss remain largely unknown. In our study, we were unable to find a consistent association of any of the assessed metabolic variables with postoperative changes in QTc interval length. In particular, we did not find a correlation between the postoperative decline in circulating insulin levels and the QTc interval shortening. Insulin appeared to be a most likely mediator of the weight loss associated QT interval reduction [39] since the hormone is well known to increase sympathetic nervous system (SNS) activity [40] and circulating catecholamine levels [41] that strongly affect myocardial repolarization. In light of our data, however, it appears rather unlikely that the reduction of circulating insulin levels represent a major factor in this context. Since RYGB surgery is known to induce such a wide range of metabolic changes [42], it appears still likely that specific metabolic or endocrine signals that we have not captured in our study contribute to the observed QTc interval shortening. For instance, free fatty acids (FFAs) may represent a good candidate since one previous study [22] has found a correlation between the decline in circulating FFA levels and the QTc interval length reduction after diet-induced weight loss. Also, the adipose tissue hormone leptin may be a good candidate since it was shown to decline after bariatric surgery along with a marked reduction in SNS activity [43]. Beside these putative hormonal mediators, other mechanisms may also contribute to the weight loss associated reduction in QT interval length. For instance, it is well documented that obesity leads to enhanced cardiac fat deposits, which might also impact on ventricular repolarization, but are likely decline with weight loss. Also, a reduction in subclinical ventricular hypertrophy or sleep apnoea/hypopnoea after bariatric surgery that has not been captured in our current study could have an important impact on myocardial repolarization. Putting this forward, further research is clearly in need to pinpoint the underlying mechanisms of weight loss associated QT interval length reduction.

QT dispersion did not change after RYGB surgery in our study, i.e. a finding that is in contrast to previous findings. A recent meta-analyses of seven studies [23] investigating QT dispersion after weight loss found a reduction of QT dispersion in six of the studies. Of note, QT dispersion was corrected for HR by using the Bazett's equation in five of these studies and HR changes associated with weight loss were reported only in four of these studies, with two of them showing a clear reduction in HR. Overall, there is no evidence that QT dispersion depends on HR and it has elegantly been shown that a QT dispersion correction for HR by using the Bazett's equation can produce invalid results in particular when there is a difference in HR [44]. On the background of our negative finding and the outlined methodological considerations, we believe that it remains unclear whether or not weight loss affects QT dispersion.
Several limitations of our study should be mentioned. First, the limited number of patients and the overrepresentation of women did not allow us to test for putative sex differences. Second, since our study includes patients with diabetes, albeit to a very limited percentage, i.e. $18 \%$, we cannot exclude that established autonomic neuropathy have biased QT interval results in some of the patients. Lastly, we were unable to obtain data on SNS activity, sleep-related disordered breathing and other variables that could contribute to the reduction of QTc interval length after the surgically induced weight loss.

\section{Conclusion}

The findings of our study clearly support the previous notion of QTc interval shortening in response to weight loss. However, our finding that the extent of QTc interval changes in response to a bariatric surgery induced weight loss largely depends on the applied HR correction equation calls the clinical significance of obesity and weight loss associated QTc interval alterations into question. Thus, our results may stimulate other researchers to also apply other than Bazett's correction equation in future studies and probably also on already existing database, in order to elucidate the important question as to whether the weight loss associated QT interval shortening reduces the risk of cardiac arrhythmia and sudden death in obesity.

Acknowledgment We are very grateful to Dr. Cathriona R. Monnard, Ph.D. (Department of Physiology/Medicine, University of Fribourg, Switzerland) for improving the English language of this manuscript.

Conflict of Interest The authors declare that they have no conflict of interest.

Ethical Approval All procedures performed in studies involving human participants were in accordance with the ethical standards of the institutional and/or national research committee and with the 1964 Helsinki Declaration and its later amendments or comparable ethical standards.

Informed Consent Informed consent was obtained from all individual participants included in the study.

\section{References}

1. Poirier P, Giles TD, Bray GA, et al. Obesity and cardiovascular disease: pathophysiology, evaluation, and effect of weight lossan update of the 1997 American Heart Association scientific statement on obesity and heart disease from the obesity committee of the council on nutrition, physical activity, and metabolism. Circulation. 2006;113:898-918. 
2. Plourde B, Sarrazin JF, Nault I, et al. Sudden cardiac death and obesity. Expert Rev Cardiovasc Ther. 2014;12:1099-110.

3. Straus S, Kors JA, De Bruin ML, et al. Prolonged QTc interval and risk of sudden cardiac death in a population of older adults. J Am Coll Cardiol. 2006;47:362-7.

4. Frank S, Colliver JA, Frank A. The electrocardiogram in obesity: statistical analysis of 1,029 patients. J Am Coll Cardiol. 1986;7: 295-9.

5. Alpert MA, Nusair MB, Mukerji R, et al. Effect of weight loss on ventricular repolarization in normotensive severely obese patients with and without heart failure. Am J Med Sci. 2015;349:17-23.

6. Al-Salameh A, Allain J, Jacques A, et al. Shortening of the QT interval is observed soon after sleeve gastrectomy in morbidly obese patients. Obes Surg. 2014;24:167-70.

7. Pontiroli AE, Merlotti C, Veronelli A, et al. Effect of weight loss on sympatho-vagal balance in subjects with grade-3 obesity: restrictive surgery versus hypocaloric diet. Acta Diabetol. 2013;50:843-50.

8. Mukerji R, Petruc M, Fresen JL, et al. Effect of weight loss after bariatric surgery on left ventricular mass and ventricular repolarization in normotensive morbidly obese patients. Am J Cardiol. 2012;110:415-9.

9. Gondoni LA, Titon AM, Montano M, et al. The myth of QT shortening by weight loss and physical training in obese subjects with coronary heart disease. Obesity (Silver Spring). 2011;19:200-3.

10. Alam I, Lewis MJ, Lewis KE, et al. Influence of bariatric surgery on indices of cardiac autonomic control. Auton Neurosci. 2009;151: 168-73.

11. Russo V, Ammendola E, De Crescenzo I, et al. Effect of weight loss following bariatric surgery on myocardial dispersion of repolarization in morbidly obese patients. Obes Surg. 2007;17:857-65.

12. Bezante GP, Scopinaro A, Papadia F, et al. Biliopancreatic diversion reduces QT interval and dispersion in severely obese patients. Obesity (Silver Spring). 2007;15:1448-54.

13. Pontiroli AE, Pizzocri P, Saibene A, et al. Left ventricular hypertrophy and QT interval in obesity and in hypertension: effects of weight loss and of normalisation of blood pressure. Int $\mathrm{J}$ Obes Relat Metab Disord. 2004;28:1118-23.

14. Papaioannou A, Michaloudis D, Fraidakis O, et al. Effects of weight loss on QT interval in morbidly obese patients. Obes Surg. 2003;13:869-73

15. Gupta AK, Xie B, Thakur RK, et al. Effect of weight loss on QT dispersion in obesity. Indian Heart J. 2002;54:399-403.

16. Mshui ME, Saikawa T, Ito K, et al. QT interval and QT dispersion before and after diet therapy in patients with simple obesity. Proc Soc Exp Biol Med. 1999;220:133-8.

17. Pietrobelli A, Rothacker D, Gallagher D, et al. Electrocardiographic QTc interval: short-term weight loss effects. Int J Obes Relat Metab Disord. 1997;21:110-4.

18. Carella MJ, Mantz SL, Rovner DR, et al. Obesity, adiposity, and lengthening of the QT interval: improvement after weight loss. Int J Obes Relat Metab Disord. 1996;20:938-42.

19. Doherty JU, Wadden TA, Zuk L, et al. Long-term evaluation of cardiac function in obese patients treated with a very-low-calorie diet: a controlled clinical study of patients without underlying cardiac disease. Am J Clin Nutr. 1991;53:854-8.

20. Rasmussen LH, Andersen T. The relationship between QTc changes and nutrition during weight loss after gastroplasty. Acta Med Scand. 1985;217:271-5.

21. Seyfeli E, Duru M, Kuvandik G, et al. Effect of weight loss on QTc dispersion in obese subjects. Anadolu Kardiyol Derg. 2006;6:1269.

22. Corbi GM, Carbone S, Ziccardi P, et al. QT intervals in obese women with visceral adiposity: effects of sustained weight loss over 1 year. J Clin Endocrinol Metab. 2002;87:2080-3.
23. Omran J, Firwana B, Koerber S, et al. Effect of obesity and weight loss on ventricular repolarization: a systematic review and metaanalysis. Obes Rev. 2016;17(6):520-30.

24. Ferrannini E, Mingrone G. Impact of different bariatric surgical procedures on insulin action and $\beta$-cell function in type 2 diabetes. Diabetes Care. 2009;32:514-20.

25. van Noord C, Sturkenboom M, Straus S, et al. Serum glucose and insulin are associated with QTc and RR intervals in nondiabetic elderly. Eur J Endocrinol. 2010;162:241-8.

26. Brown DW, Giles WH, Greenlund KJ, et al. Impaired fasting glucose, diabetes mellitus, and cardiovascular disease risk factors are associated with prolonged QTc duration. Results from the third national health and nutrition examination survey. J Cardiovasc Risk. 2001;8:227-33.

27. Gastaldelli A, Emdin M, Conforti F, et al. Insulin prolongs the QTc interval in humans. Am J Physiol Regul Integr Comp Physiol. 2000;279:R2022-5.

28. Iacobellis G, Curione M, Di Bona S, et al. Effect of acute hyperinsulinemia on ventricular repolarization in uncomplicated obesity. Int J Cardiol. 2005;99:161-3.

29. Yap YG, Camm AJ. Drug induced QT prolongation and torsades de pointes. Heart. 2003;89:1363-72.

30. Thurnheer M, Bisang P, Ernst B, et al. A novel distal very long roux-en y gastric bypass (DVLRYGB) as a primary bariatric procedure - complication rates, weight loss, and nutritional $/$ metabolic changes in the first 355 patients. Obes Surg. 2012;22:1427-36.

31. Moss AJ. Measurement of the QT interval and the risk associated with QT(c) interval prolongation - a review. Am J Cardiol. 1993;72:B23-5.

32. Bazett HC. An analysis of the time-relations of electrocardiograms. Ann Noninvasive Electrocardiol. 1997;2:177-94.

33. Fridericia LS. Die Systolendauer im Elektrokardiogramm bei normalen Menschen und bei Herzkranken. Acta Med Scand. 1920;53:469-86.

34. Sagie A, Larson MG, Goldberg RJ, et al. An improved method for adjusting the QT interval for heart rate (the Framingham Heart Study. Am J Cardiol. 1992;70:797-801.

35. Hodges M, Salerno Q, Erlien D. Bazett's QT correction reviewed. Evidence that a linear qt correction for heart rate is better. J Am Coll Cardiol. 1983;1:694.

36. Matthews DR, Hosker JP, Rudenski AS, et al. Homeostasis model assessment: insulin resistance and beta-cell function from fasting plasma glucose and insulin concentrations in man. Diabetologia. 1985;28:412-9.

37. Adams TD, Davidson LE, Litwin SE, et al. Health benefits of gastric bypass surgery after 6 years. JAMA. 2012;308:1122-13.

38. Sjöström L, Peltonen M, Jacobson P, et al. Bariatric surgery and long-term cardiovascular events. JAMA. 2012;307:56-65.

39. Maser RE, Lenhard MJ, Peters MB, et al. Effects of surgically induced weight loss by roux-en-Y gastric bypass on cardiovascular autonomic nerve function. Surg Obes Relat Dis. 2013;9:221-6.

40. Anderson EA, Hoffman RP, Balon TW, et al. Hyperinsulinemia produces both sympathetic neural activation and vasodilation in normal humans. J Clin Invest. 1991;87:2246-52.

41. Kern W, Peters A, Born J, et al. Changes in blood pressure and plasma catecholamine levels during prolonged hyperinsulinemia. Metabolism. 2005;54:391-6.

42. Gralka E, Luchinat C, Tenori L, et al. Metabolomic fingerprint of severe obesity is dynamically affected by bariatric surgery in a procedure-dependent manner. Am J Clin Nutr. 2015;102:1313-22.

43. Seravalle G, Colombo M, Perego P, et al. Long-term sympathoinhibitory effects of surgically induced weight loss in severe obese patients. Hypertension. 2014;64:431-7.

44. Malik M, Camm AJ. Mystery of QTc interval dispersion. Am J Cardiol. 1997;79:785-7. 